\title{
Development of a new submersible test to characterise the erosion of soils and sediments
}

\author{
O. Ndoye, C. Chevalier, P. Reiffsteck, C. Minatchy, S. Fanelli \\ Université Paris-Est, IFSTTAR, GERS, SRO, Marne-la-Vallée, France \\ D. Pham-Van-Bang \\ Université Paris-Est, Laboratory for Hydraulics Saint-Venant (LHSV), Chatou, France
}

\begin{abstract}
Understanding the mechanism and behavior of the scour process is a most challenging subject. One part of this challenge is the in situ measurement of soil and sediment sensitivity to erosion (in undisturbed and submersible conditions). To improve this understanding, a new test, the Wheel Erosion Test (WET), was developed. It consists of a wheel rotating upon a layer of sediments located in an aquarium filled in with water. The rotating speed of the wheel and the distance to the sediment bed are the main control parameters. If the bed shear stress produced by the wheel is sufficient, grains are eroded and a scour hole is observed. The dimensions of the scour hole (length, width and depth) can be determined by video camera and acoustic measurements allowing the quantification of erosion strength. A first parametric study on Fontainebleau sand validating the principle of the WET is reported.
\end{abstract}

\section{INTRODUCTION}

Managing the scour risk of civil structures such as bridge piers, river beds or river banks exposed to natural hazards (flooding, extreme water flow conditions, dam failure, etc.) constitutes a major challenge to sustainable development and land use planning. The scouring processes represent a significant contributing factor in the destruction of structures and are thus a major field of research activities (Chevalier et al. 2014).

Scour is defined as a combination of several phenomena including local erosion around structures (Hoffmans et al. 1997, May et al. 2002, Richardson et al. 2001). For example, the studies of Anerson et al. (2012) and Sheppard et al. (2005) have focused on the physical phenomenon of horseshoe vortex, highlighting their impact on the erosion around a bridge pier. Until now, the prediction of scour depth is mostly based on empirical equation.

Understanding the mechanism and behavior of the scour process is thus a most challenging subject and one part of this challenge is the in situ measurement of soil and sediment sensitivity to erosion (in undisturbed and submersible conditions).

Several devices have already been developed to measure the sensitivity of the soil to erosion (or erodibility), including jet erosion tests (Hanson, 2004, Reiffsteck et al. 2012), the Erosion Function Apparatus (Briaud et al. 2001) and the Hole Erosion Test (Chevalier et al. 2010, Haghighi et al. 2013, Wan \& Fell 2004). Results from these various tests, however, are typically not easily correlated, especially when considering laboratory and in situ tests. Moreover, these tests cannot be used in submerged conditions. The best way to study the erodibility of sediments is thus to make direct in situ measurements (Jerez et al. 2012).

To overcome these limits, a new test was developed: the Wheel Erosion Test (WET). The original erosion set-up is based on a submerged cylinder (wheel) rotating around a horizontal axis upon a layer of sediments. The rotating cylinder $(13 \mathrm{~cm}$ width and $10 \mathrm{~cm}$ diameter) generates a flow of the surrounding water which applies a shear stress on the sediment bed. If this stress is sufficiently large, grains are eroded and a scour hole is observed. During a test, the scour hole is characterised by video cameras and acoustic measurements at different times. These measurements allow the characterization of erosion strength.

This paper is structured as follows. The first part deals with the experiment set-up, the measurement methods and the test procedures. The second part presents a first parametric study on Fontainebleau sand in order to validate the principle of the WET. The last section draws some conclusions and perspectives. 


\section{EXPERIMENTAL SET UP AND PROCEDURE}

\subsection{Principle of the Wheel Erosion Test (WET)}

The original erosion set-up is based on a submerged cylinder (wheel) which rotates around a horizontal axis upon an initially flat sediment bed. The wheel in rotation generates a flow of the surrounding water that applies a stress on the grain surface. If this stress is sufficient, grains are eroded and a scour hole is observed. The wheel can thus rotate at different velocities and at different vertical positions modifying the action of water on sediment surface.

During or after a test, the scour hole is characterized by video cameras and acoustic measurements thus enabling to determine the difference between the initial and the final level of the surface of sediments and thus his resistance to erosion.

The velocity of the wheel $\left(V_{W}\right)$, the initial distance between the surface of sediments and the wheel $\left(H_{i}\right)$ are the main control parameters.

\subsection{Experimental apparatus}

The experiment (Fig. 1) is composed by different parts:

- an aquarium $(120 \mathrm{~cm}$ long, $50 \mathrm{~cm}$ width, $50 \mathrm{~cm}$ high) filled in with $41 \mathrm{~cm}$ of water and a layer of $7 \mathrm{~cm}$ of sediment;

- a steel frame supporting a mobile support on which the wheel $(10 \mathrm{~cm}$ diameter and $13 \mathrm{~cm}$ width) is fixed. The mobile support enables displacement along the vertical axis $\mathrm{ZZ}$ ' in order to adjust the initial distance $\left(H_{i}\right)$ to the desired value;

- a motor, mounted on the steel frame, that allows the rotation speed of the wheel $\left(V_{W}\right)$ to be controlled;

- a leveler that allows uniforming the surface of sediment.

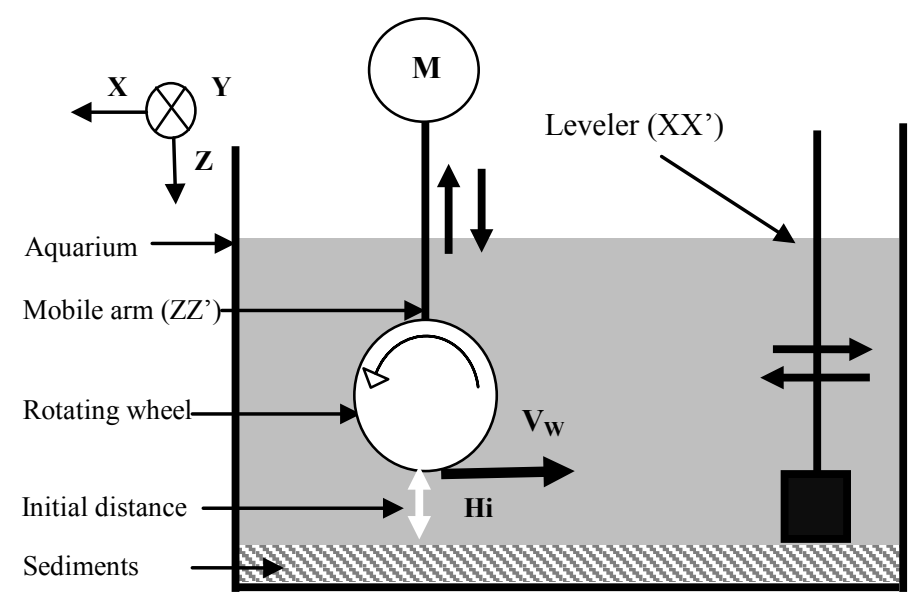

Figure 1. Experimental set-up.

\subsection{Measurement methods}

Two methods are used to measure the dimensions (length, depth, width) of the scour hole. The mobile support must be at its highest vertical position before the measurements.

\subsubsection{Optical measurements}

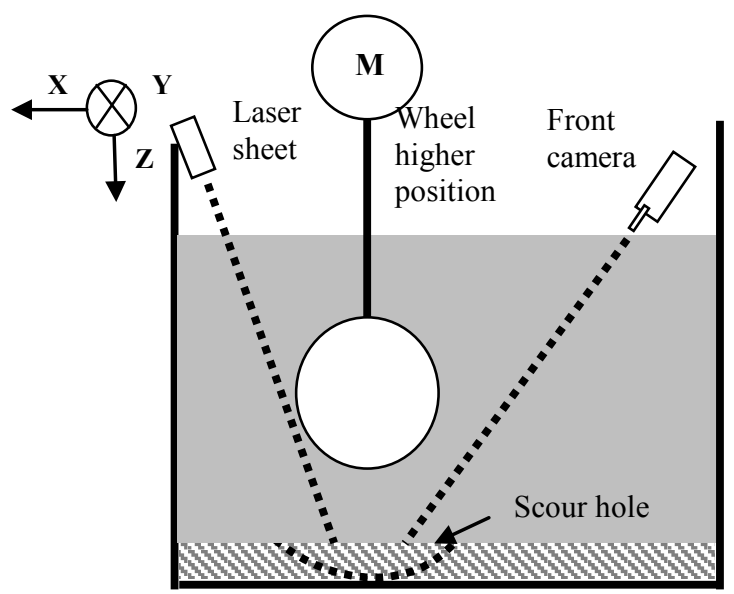

Figure 2. Optical measurement apparatus.

Optical method is a very convenient technique used to study scouring process around model bridge pier (Defanti et al. 2010). A laser sheet is used to analyze the temporal evolution of the surface due to erosion processes. It allows to measure the depth of scour hole on the $\mathrm{YZ}$ plan. Due to a problem of visibility, the optical method could not be used for cohesive soils because of the turbidity caused by the particles.

The optical method (Fig. 2) consists of recording with a camera a laser ray projection on the eroded layer of sediments $\left(L_{t}\right)$ and compare it to the initial laser ray projection $\left(L_{0}\right)$.

The laser sheet and the camera are both fixed on the steel frame. Figure 3 shows results obtained with the optical measurement method.

$$
\left(L_{0}\right)
$$

Figure 3. Optical recording.

The measuring system have to be calibrated by recording laser ray projections of known sediment distances, thus the difference between $\left(L_{0}\right)$ and $\left(L_{t}\right)$ can be calculated according to the calibration.

\subsubsection{Acoustic measurements}

The use of acoustic method for the measurement of scour hole is convenient technique. In particular, it allows measurements in turbid water.

The principle consists of using the flight time $\left(t_{f}\right)$ of an ultrasonic wave between the lower face of an acoustic probe and the surface of sediments. By knowing the celerity of the acoustic wave in the wa- 
ter $\left(c_{a c}\right)$, the probe to sediment distance is therefore determined.

For this purpose, it is necessary to have a frequency generator, an acoustic probe and an oscilloscope (Fig. 4).

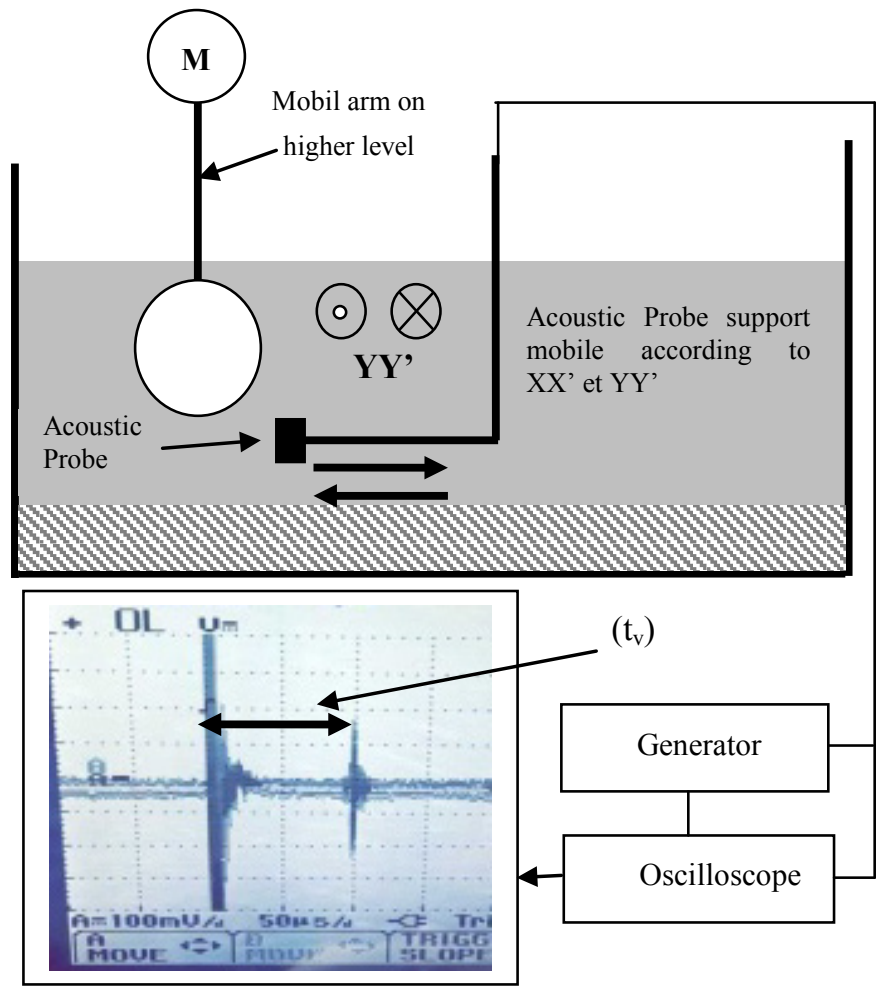

Figure 4. Acoustic measurement apparatus.

The frequency generator generates electric pulses to excite the acoustic probe that transforms the electric energy into an acoustic wave. This first step can be recorded by the oscilloscope. The acoustic wave propagates through the water and is reflected by the sediments back to the acoustic probe. The reception of the reflected wave is materialized by a second electric signal on the oscilloscope. The time between both signals represents the flight time $\left(t_{f}\right)$ of the acoustic wave and thus allow calculating the distance between the acoustic probe and the sediments:

$d_{s}=\left(\frac{c_{a c} * t_{v}}{2}\right)$.

The acoustic probe is mounted on a support that can move in a (X-Y) plane and provide bathymetry measurements. It thus allows to determinate the scour depth $\left(h_{f}(x, y)\right)$ on several points by subtracting the initial distance $\left(d_{s 0}\right)$ to the measured distance $\left(d_{s}(x, y)\right)$ :

$h_{f}(x, y)=d_{s}(x, y)-d_{s 0}$.

\subsection{Procedure}

\subsubsection{Placement of the material}

The Fontainebleau sand, used in the present study, is known for being a monodispersed material. Figure 5 presents the grading curve of the Fontainebleau sand. In the procedure, the pluviation method (Cresswell and al. 1997) is used in the aquarium to place sediments. The settling of sediment grains in water is sufficiently slow to neglect the presence of air trapped in the sediments.

Once the material is placed, the leveler is used to create a uniform sediment surface. Then the wheel is positioned at the desired initial distance $\left(H_{i}\right)$. Finally the velocity of the wheel $\left(V_{W}\right)$ is prescribed and the erosion test starts.

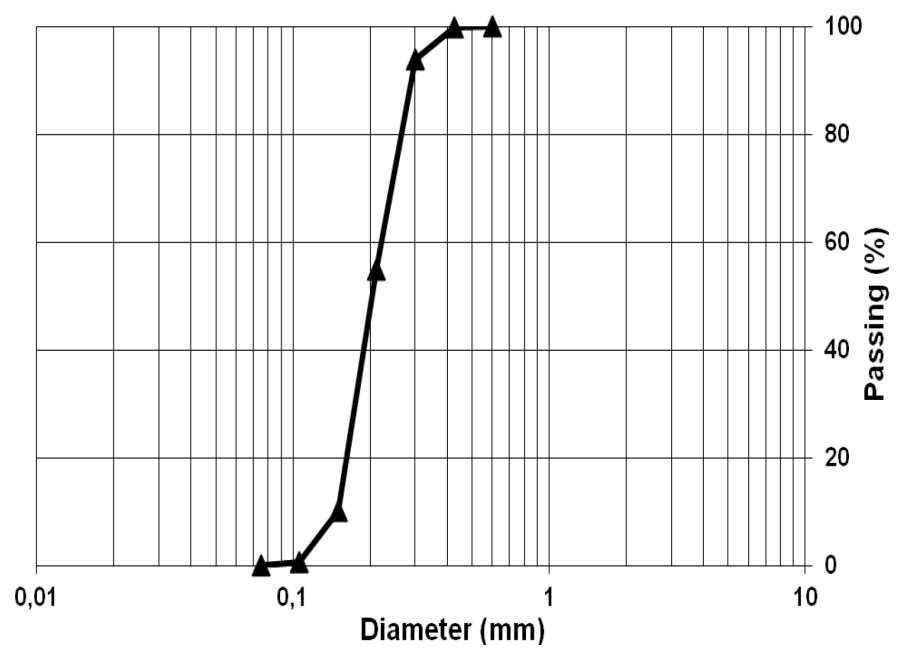

Figure 5 Grading curve of Fontainebleau sand.

\subsubsection{Erosion test campaign}

Three types of tests are used: tests in an almost permanent regime (TPR), tests by steps of time (TST) and tests by steps of velocity (TSV).

A TPR is a continuous test for which the two control parameters $\left(H_{i}, V_{W}\right)$ are kept constant at fixed value during all the test, i.e. 20 minutes. After this duration, the permanent and final dimension of the scour hole is measured.

A TST is a test similar to TPR, but the rotation of the wheel is interrupted at different times $\{1 \mathrm{~min}$; $2 \mathrm{~min}$; $5 \mathrm{~min}$; $10 \mathrm{~min} ; 20 \mathrm{~min}\}$ in order to realize intermediate measurements with acoustic method, in particular (cf. 2.3). After each measurement, excepted the one at 20 minutes, the wheel is lowered again at the same position $\left(H_{i}\right)$ and restarted at the same velocity $\left(V_{W}\right)$.

A TSV is a succession of tests, without resetting the initial level of sediments, in which the velocity $\left(V_{W}\right)$ is increased every 20 minutes. 
Table 1. Erosion test campaign on Fontainebleau sand.

\begin{tabular}{lcccc}
\hline Tests & $\begin{array}{c}\text { Initial dis- } \\
\text { tance }\end{array}$ & $\begin{array}{c}\text { Rotation } \\
\text { speed }\end{array}$ & $\begin{array}{c}\text { Velocity on } \\
\text { border }\end{array}$ & $\begin{array}{c}\text { Running } \\
\text { time }\end{array}$ \\
\cline { 2 - 5 } & $H_{i} \mathrm{~cm}$ & $\mathrm{rpm}$ & $V_{W} \mathrm{~m} / \mathrm{s}$ & $\min$ \\
\hline TPR & 0.5 & 60 & 0.31 & 20 \\
TPR & 0.5 & 90 & 0.47 & 20 \\
TPR & 0.5 & 120 & 0.62 & 20 \\
TPR & 0.5 & 150 & 0.78 & 20 \\
TPR & 1 & 90 & 0.47 & 20 \\
TPR & 1 & 120 & 0.62 & 20 \\
TPR & 1 & 150 & 0.78 & 20 \\
TPR & 2 & 90 & 0.47 & 20 \\
TPR & 2 & 120 & 0.62 & 20 \\
TPR & 2 & 150 & 0.78 & 20 \\
TST & 0.5 & 150 & 0.78 & 20 \\
TSV & 0.5 & $60-90-120-$ & $0.31 / 0.47 /$ & 80 \\
& & 150 & $0.62 / 0.78$ & \\
\hline
\end{tabular}

\section{RESULTS}

\subsection{Topography of the scour holes}

When the rotation speed $\left(V_{W}\right)$ is sufficiently rapid to induce bed shear stress larger than critical value for erosion, an erosion pattern is observed. It is composed by a hole and two areas of deposit located upstream and downstream of the wheel. The deposit at the downstream side is bigger than the one at the upstream side (Fig. 6). There is also symmetry with respect to the XZ plane.

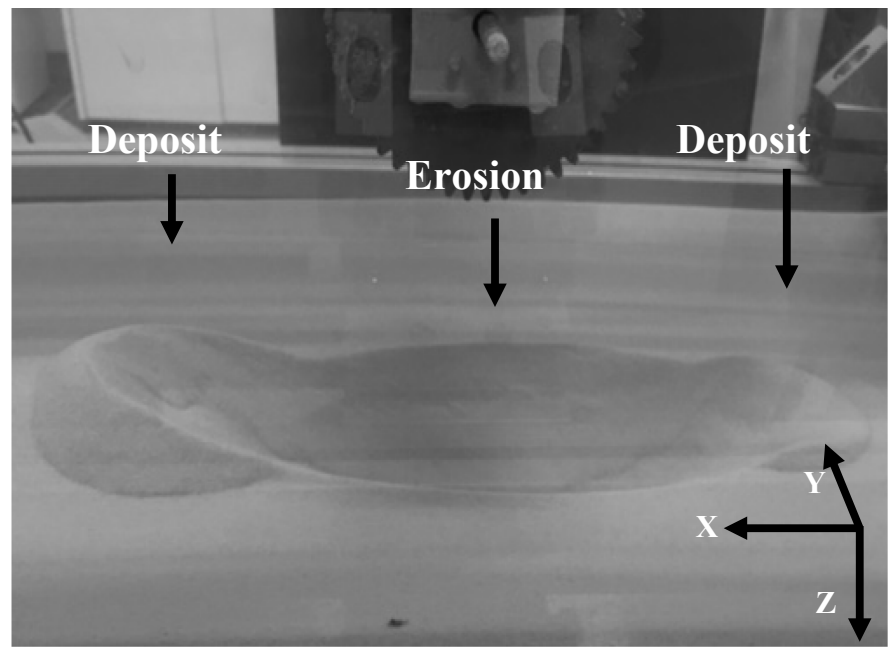

Figure 6. Scour hole (final size) after TPR test for $\left(H_{i}, V_{W}\right)=$ $(0.5 \mathrm{~cm}, 0.78 \mathrm{~m} / \mathrm{s})$.

\subsection{Analysis and interpretation of results}

\subsubsection{Acoustic results}

Figures 7-8 present results on scour holes for two tests in identical conditions except for the initial distance $\left(H_{i}\right)$.

\section{$\mathbf{Y}(\mathbf{c m})$}
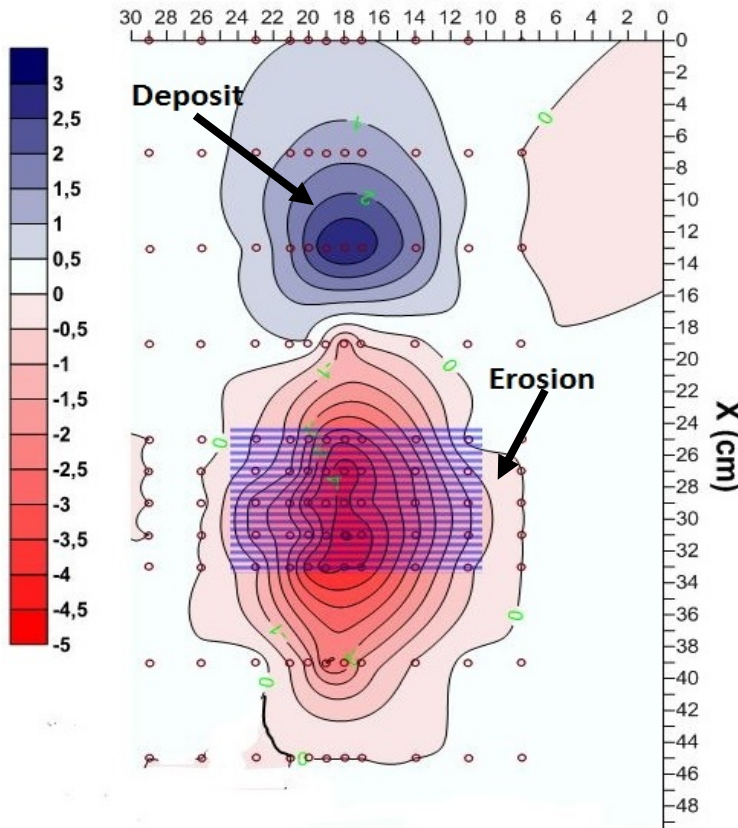

Figure 7. Scour hole (final size) after TPR test for $\left(H_{i}, V_{W}\right)=$ $(2 \mathrm{~cm}, 0.78 \mathrm{~m} / \mathrm{s})$ with acoustic measurements.

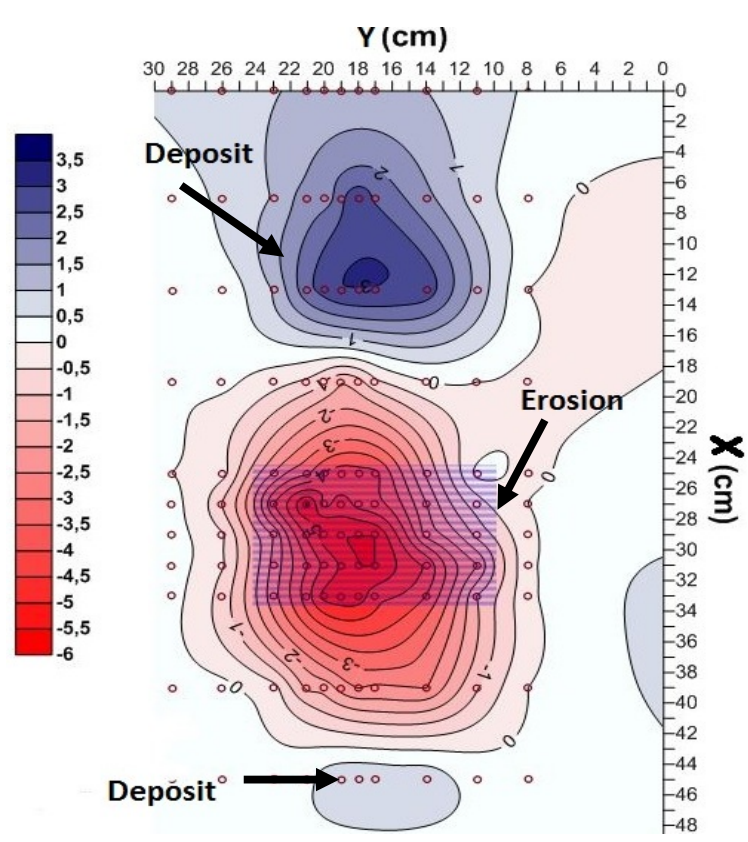

Figure 8. Scour hole (final size) after TPR test for $\left(H_{i}, V_{W}\right)=$ $(0.5 \mathrm{~cm}, 0.78 \mathrm{~m} / \mathrm{s})$ with acoustic measurements.

From acoustic measurements of erosion patterns, the effect of the initial distance $\left(H_{i}\right)$ is particularly illustrated. The dimensions of the hole and of the area of deposit decrease with the increase of the initial distance $\left(H_{i}\right)$. The wheel being more distant from the initial surface, this is correlated to a diminution of the stress applied by the fluid on the sediments. Note that, in agreement to that observation, tests made in an almost permanent regime (TPR) also show that the dimensions (length, depth, width) of the scour hole increase as a function of the velocity $\left(V_{W}\right)$ for the same initial distance $\left(H_{i}\right)$. 


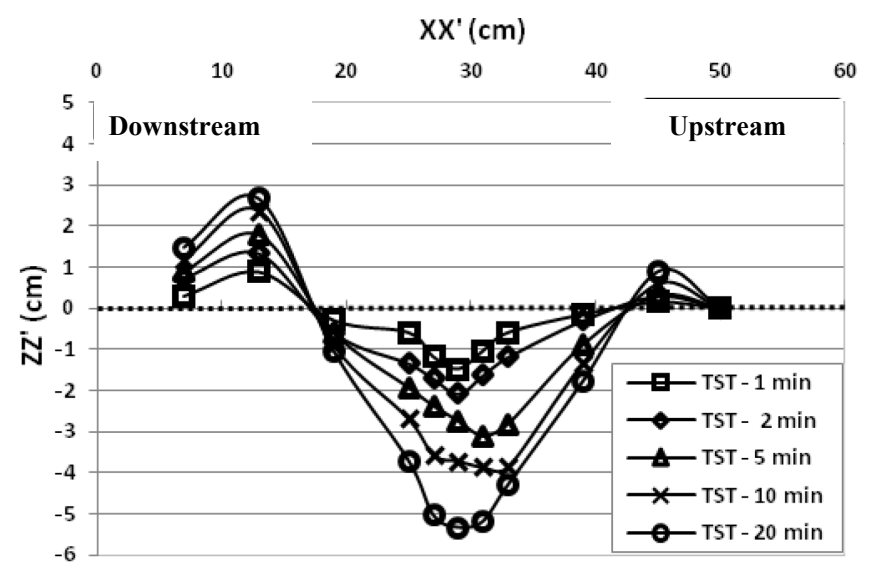

Figure 9. TST - Scour profiles obtained with acoustic measurements according to XZ with $H_{i}=0,5 \mathrm{~cm}$ and $V_{W}=0,78 \mathrm{~m} / \mathrm{s}$.

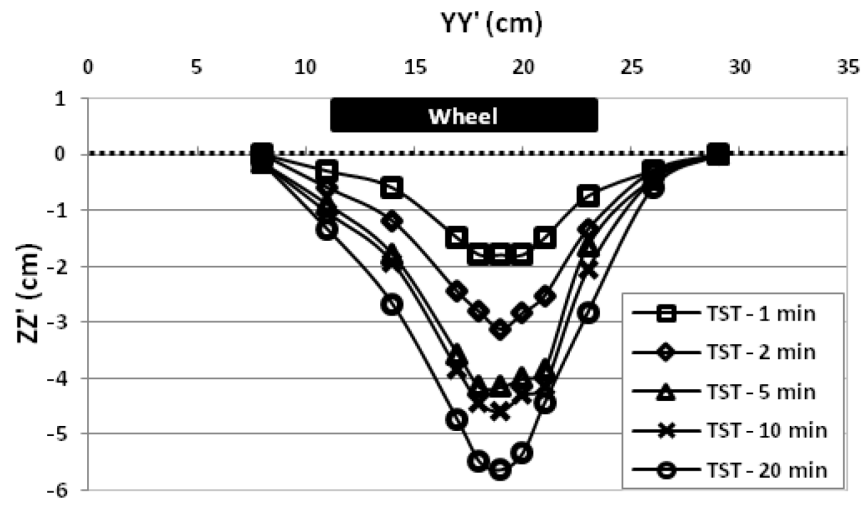

Figure 10. TST - Scour profiles obtained with acoustic measurements according to $\mathrm{XZ}$ with $H_{i}=0,5 \mathrm{~cm}$ and $V_{W}=0,78 \mathrm{~m} / \mathrm{s}$.

Figures 9-10 show the evolution of the scour hole according to both planes $\mathrm{XZ}$ and $\mathrm{YZ}$ at times equal to $\{1 \mathrm{~min} ; 2 \mathrm{~min} ; 5 \mathrm{~min} ; 10 \mathrm{~min} ; 20 \mathrm{~min}$ \} for the test by steps of time (TST). The stress exerted by the fluid on the sediments due to the rotation of the wheel induce the formation of both the scour hole and the upstream deposit area in the first minute of the test.

The shapes of the curves at two minutes are marked on the one hand by the formation of the downstream deposit area (Fig. 9a) and on the other hand by the increase of the maximum depth. The length and the width are quasi equal. The dimensions of the scour hole and the deposits area subsequently increase until the last step of the test $(20$ minutes).

The position of the maximum depth is aligned with the center of the wheel where the hydrodynamic forces are important. The evolution in length and width of the scour hole are clearly less important than the increase in depth of the pit. This explains the progressive increase of the slopes of the scour hole during the test.

The test by steps of velocity (TSV) has been conducted in order to study the effect of flow velocity magnitude on the dimension of scour holes. Figures 11-12 present the final (after 20 minutes) dimension of scour hole which are obtained for each step of velocity.

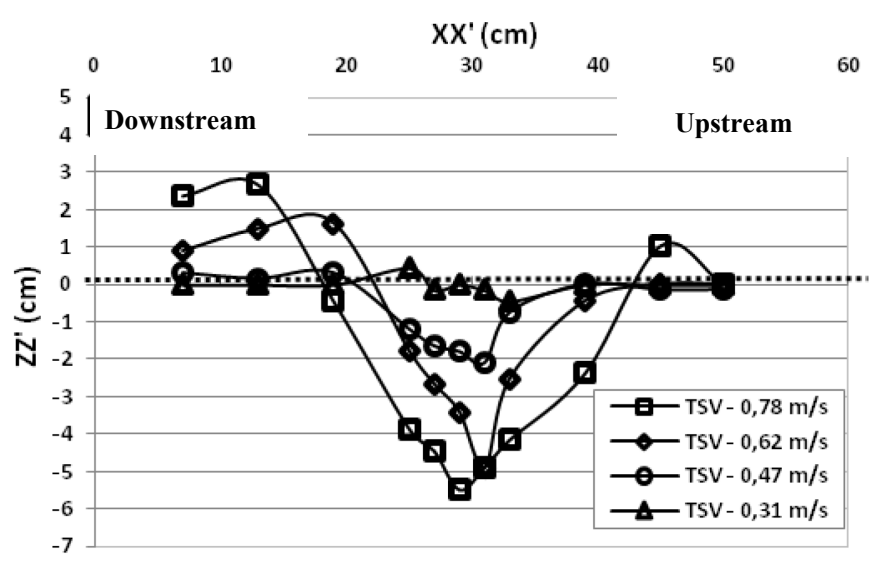

Figure 11. TSV - Scour profiles obtained with acoustic measurements according to $\mathrm{XZ}$.

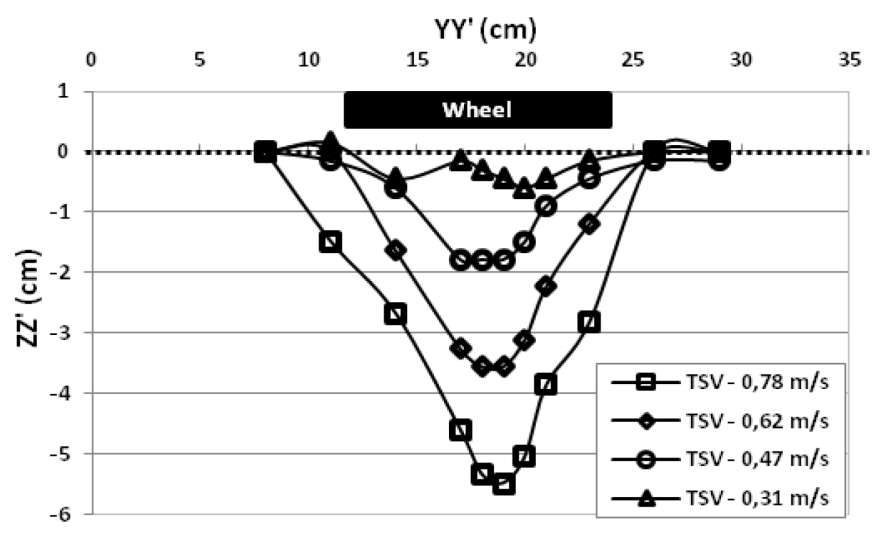

Figure 12. TSV - Scour profiles obtained with acoustic measurements according to $\mathrm{XZ}$.

It can be observed, on both figures, that even for low velocity sediment transport occurs. But the erosion pattern obtained at low velocity is very different from what is observed at higher velocity (see TST at 1 minute; Fig 9-10).

Indeed, for low velocity (equal to $0.31 \mathrm{~m} / \mathrm{s}$ ), a non-unique hole is observed but multiple (at least two) holes: this is probably due to some hydrodynamic instabilities. For larger velocity, these holes merge (or coalesces) to form a unique hole. This could mean that there is different threshold of stress to both the sediments transport and the hydrodynamic instabilities. As expected, the dimensions of the scour hole increase with the velocity $\left(V_{W}\right)$ and the position of the maximum depth remains aligned with the center of the wheel.

The test by steps of velocity (TSV) and the test by steps of time (TST) were realized with the same initial distance $\left(H_{i}\right)$, knowing that the last step of velocity (for TSV) or of time (for TST) can be compare to the test in an almost permanent regime (TPR) realized with the same initial distance and the same (final) velocity.

Thus it is possible to cross compare the results of the three type of tests to study the robustness of the WET. 
Comparison of TPR, TSV and TST results is illustrated by Figures 13-14 according to $\mathrm{XZ}$ and $\mathrm{YZ}$ planes. A very good agreement is obtained as the 3 profiles in both planes are really similar. These results mean that the final erosion shape does not depend on the history of the test.

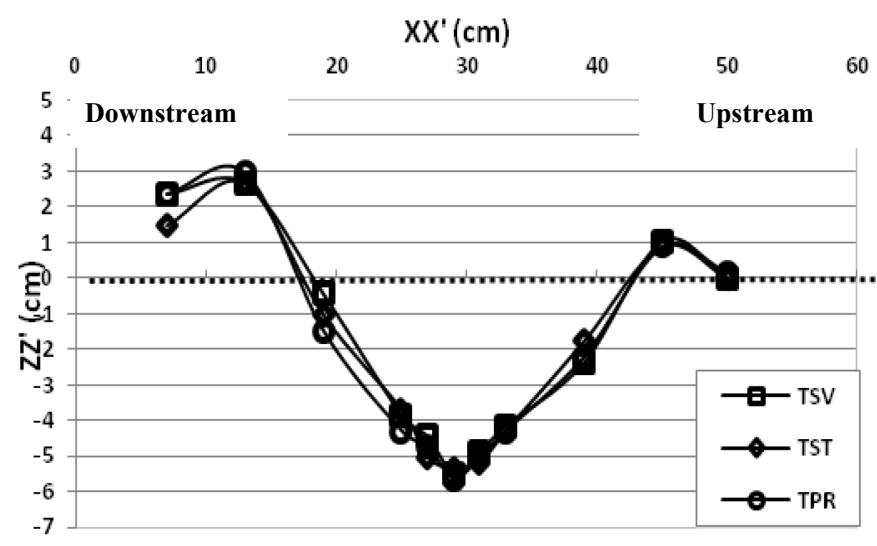

Figure 13. TSV - TST - TPR - Scour profiles according to XZ.

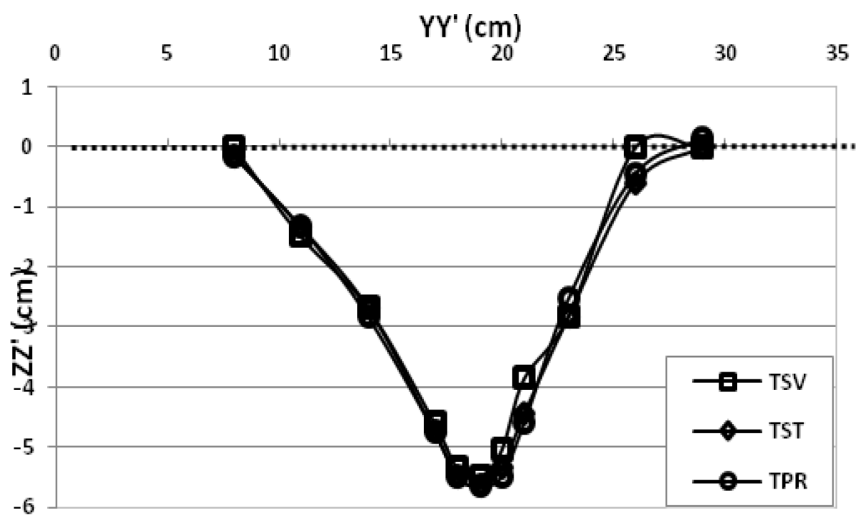

Figure 14. TSV - TST - TPR - Scour profiles according to YZ.

\subsubsection{Comparison between acoustic and optical re- sults}

Figure 15 shows on one hand the maximum scour depths calculated with both the optical method and the acoustic method for all the TPR $\left(H_{i}=0.5,1\right.$ and 2 $\mathrm{cm})$.

The comparisons are satisfactory even if it is necessary to make a more detailed analysis. The curve shows an increase of the dimensions of the scour hole according to both the velocity $\left(V_{W}\right)$ and the initial distance $\left(H_{i}\right)$. For $H_{i}=0.5 \mathrm{~cm}$ and $V_{W}=0.31$ $\mathrm{m} / \mathrm{s}$, the sediment transport is quite weak. This means that the corresponding bed shear stress is slightly larger than the threshold for motion.

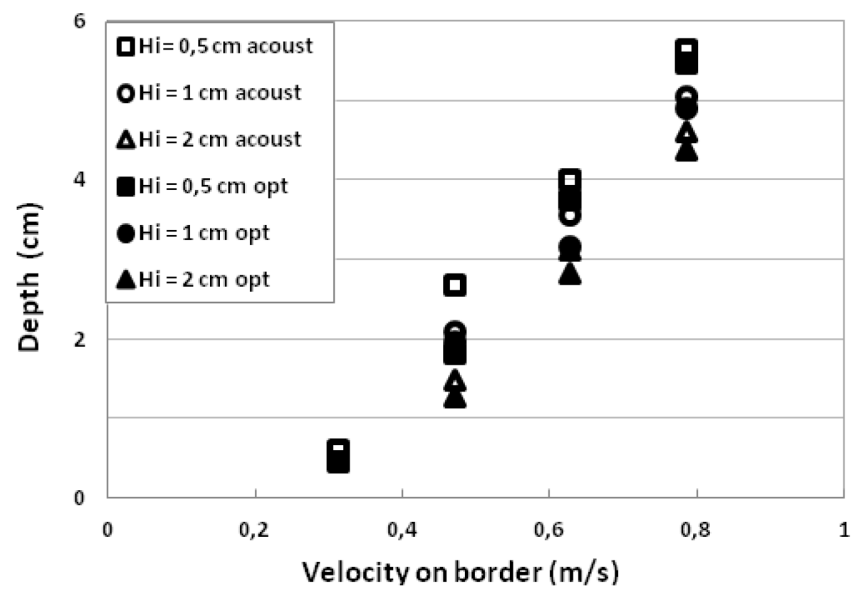

Figure 15. Comparison of the two measurement method.

\section{CONCLUSION AND PERSPECTIVES}

The Wheel Erosion Test (WET) has been developed to measure sensitivity of immersed sediments to erosion (erodability). This paper reported the development and a first parametric study which was made on Fontainebleau sand using many approach by diversifying the protocols.

The results show that when erosion occurs, the quantity of eroded sediments increases according to the velocity of wheel rotation $\left(V_{W}\right)$. In fact, the flow generated by the device allows sediments to be eroded by changing $\left(V_{W}\right)$ and $\left(H_{i}\right)$. Results obtained from the test by steps of time coincide with the results of the test made with an almost permanent regime; the dimensions of the scour hole obtained after the test by stage of velocity are also demonstrating the robustness of the Wheel erosion Test device.

So the device allows testing the susceptibility of sediments to erosion. The results present a high potential to develop a macroscopic law of erosion, which will take into account the relation between the variation of the velocity $\left(V_{W}\right)$ and the initial distance $\left(H_{i}\right)$. However to demonstrate it and so validate the WET device, it is further required to develop a model relating (local) bed shear stress to (macroscopic) rotation speed of the wheel.

As outlined above, the present study was realized on a not cohesive material. It is essentially necessary to start by testing known materials, easy to prepare and manipulate thus avoiding uncertainties. To continue testing the robustness of the device WET, the next step of the study concerns the cohesive sediments (mixture of Fontainebleau - Armorican Kaolinite, see Lachaussée et al 2016) by using same protocols to integrate the characteristics of the material in the development of the model aiming to determine the stress on the interface water-sediments.

Further approaches are undergoing development, in particular adding an ambient current during the test. This could be done in hydraulic flume similar to the one used by Lachaussée et al. (2016). 


\section{ACKNOWLEDGEMENT}

The present work benefits from the financial support of the ANR French Research Agency within the project SSHEAR No 2014-CE03-0011 and the GIS Scientific Group of Interest in Hydraulic, Sustainable Development and Environment HEDD.

The authors acknowledge the Laboratory for Water and Environment, particularly Frédérique Larrarte, for their precious help in the instrumentation of the set-up and the preparation of the present paper.

\section{REFERENCES}

Arneson, L. A., Zevenbergen, L. W., Lagasse, P. F., and Clopper, P. E. 2012. Evaluating Scour at Bridges. Fifth Edition, Hydraulic Engineering Circular No. 18, Federal Highway Administration, Washington, D.C.

Briaud, J. L. 2001. Erosion function apparatus for scour rate predictions. J. Geotech. Geoinviron. Eng., ASCE, 127(2): 105-113.

Briaud, J. L. 2009. Abutment Scour in Cohesive Material. NCHRP Report Transportation Research Board, National Research Council, Washington. 24-15

Chevalier, C., Haghighi, I., Pham, T.L., Reiffsteck, P. 2010. Two complementary tests for characterizing the soil erosion. 5th Int. Conf. Scour Eros., ASCE, Reston, VA, 152 161.

Chevalier, C., Pham Van Bang, D., Durand, E., Charles, I., \& Herrier, G., 2014. Scour and erosion phenomena occuring in waterways recent advances. 7th Int. Conf. Scour Eros., Perth, Australia: 33-48.

Cresswell, A., Barton, M., and Brown, R., "Determining the Maximum Density of Sands by Pluviation", Geotechnical Testing Journal, 22(4): 324-328.

Defanti, E. , Giancarlo, D. P., Davide, P. 2010. An experimental studies of scour at bridge piers: collars as a countermeasure.

Haghighi, I., Chevalier, C., Duc, M., Guédon, S., Reiffsteck, P. 2013. Improvement of Hole Erosion Test and Results on Reference Soils. J. Geotech. Geoenviron. Eng., ASCE, 139(2): 330-339.

Hanson, G. J., 2004. Apparatus, test procedures, and analytical methods to measure soil erodibility in-situ. Applied Engineering in Agriculture, A.S.A.E., 20 (4): 455-462.

Hoffmans, G. and Verheij, H.J., 1997. Scour manual, Balkema, The Netherlands.

Jerez, A., Chevalier, C., Larrarte, F., 2012. Erosion measurement on immersed situations: a state of the art. 6th Int. Conf. Scour Eros, Paris, France : 27-31.

Lachaussée, F., Pham Van Bang, D., Vidal, V., Chevalier C., Ndoye, O., Szymkiewicz, F., Minatchy, C., F. Martineau, Watanabe, K., 2016. Overflow erosion on mixed kaolinsand embankments, 8th Int. Conf. Scour Eros., Oxford (this volume).

May, R.W.P., Ackers, J.C., Kirby, A.M., 2002. Manual on scour at bridges and other hydraulic structures, London.

Reiffsteck, P., Haghighi, I., Chevalier, C. 2012. Erodibility diagnostic of existing hydraulic earthworks by Mobile Jets Erosion Test. 6th Int. Conf. Scour Eros., Paris, France : 1105-1112.

Richardson, E. V. and Davis, S. R., 2001, "Evaluating Scour at Bridges - Fourth Edition, Hydraulic Engineering Circular No. 18, Federal Highway Administration Publication No. FHWA-NHI 01-001, Washington, DC, 376 p.
Sheppard, D. M., and Renna, R. 2005. Florida Scour Manual. Florida Department of Transportation, Tallahassee.

Wan et Fell , 2004. Investigation of rate of erosion of soils in embankment dams. J. Geotech. Geoinviron. Eng., ASCE, 30(4): 373-380.

\section{PREFERENCES, SYMBOLS AND UNITS}

$c_{a c}:$ acoustic wave celerity in water $(1483 \mathrm{~m} / \mathrm{s})$

$d_{s}(x, y):$ measured distance

$d_{s 0}$ : initial distance between probe and sediments

$h_{f}(x, y)$ : measured scour depth

$H_{i}$ : initial distance between wheel and sediments

$L_{0}$ : initial laser ray projection

$L_{t}$ : laser ray projection on the scour hole

TPR: Tests with an almost permanent regime

TST: Tests by Steps of Time)

TSV: Tests by Steps of Velocity.

$t_{f}$ : time flight of the acoustic wave

$V_{W}$ : velocity on the border of the wheel 